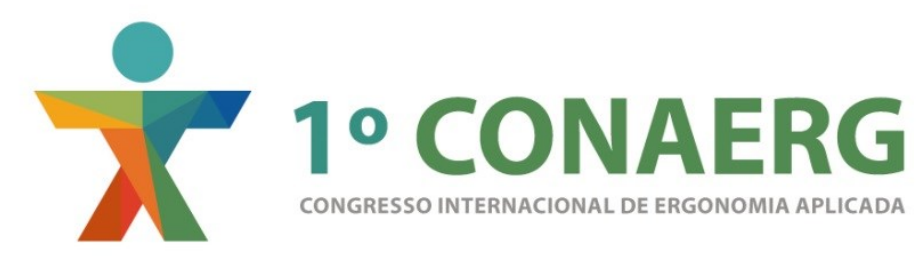

\title{
PROPOSTA METODOLÓGICA SIMPLIFICADA PARA AVALIAÇÃO PRELIMINAR DO AMBIENTE TÉRMICO EM VEÍCULOS DE TRANSPORTE COLETIVO URBANO
}

\author{
Jose Alberto Barroso Castañon (1); \\ Caio Augusto Rabite de Almeida (2) \\ Guilherme Valle Loures Brandão (3) \\ Wilian Daniel Henriques do Amaral (4) \\ (1) Universidade Federal de Juiz de Fora, D.Sc. Engenharia de Transportes \\ e-mail: jose.castanon@ufif.edu.br \\ (2) Universidade Federal de Juiz de Fora, Mestrando em Ambiente Construído \\ e-mail: caioaugusto.arq@gmail.com \\ (3) Universidade Federal de Juiz de Fora, Mestrando em Ambiente Construído. \\ e-mail: guilherme.loures@engenharia.ufff.br \\ (4) Universidade Federal de Juiz de Fora, Mestrando em Ambiente Construído. \\ e-mail: wilian.amaral@engenharia.ufff.br
}

\begin{abstract}
RESUMO
Este trabalho propõe uma metodologia simplificada para a verificação do conforto térmico no interior de veículos de transporte coletivo em meio urbano. Através de extensa revisão bibliográfica, verificouse os conceitos envolvidos e metodologias normalizadas, selecionando-se os considerados fundamentais para desenvolvimento da proposta de simplificação, que visa permitir a verificação preliminar da situação de conforto dos usuários direcionando para aplicação das normas avaliativas direcionadas ao estudo do stress térmico por calor ou frio. Após a definição da metodologia simplificada, realizaram-se medições em situação de inverno de forma a verificar e exemplificar sua aplicação.
\end{abstract}

\footnotetext{
ABSTRACT

This research proposes a simplified method to verify thermal stress inside vehicles of mass transportation in urban environment. Throughout an extensive bibliographic review, the main concepts and standard methodologies were identified and then the ones considered most representative have been selected on this proposal, which consists of verifying the preliminary status of the users' thermal comfort levels plus directing the application of proper evaluative standards on heat stress and cold stress. Field measurements were made under winter conditions after the methodology definition to verify its reliability and exemplify its application.
} 


\section{INTRODUÇÃO}

As condições ambientais exercem influência direta no comportamento e percepção dos usuários, podendo causar tensões nos indivíduos, sendo eles de ordem física ou psicológica. Nessa direção, Villarouco et al (2008) ponderam que toda atividade humana exige um determinado ambiente físico adequado para sua realização. Portanto, se considerarmos tanto a diversidade de atividades quanto a diversidade humana, podemos entender que as características do ambiente podem dificultar ou facilitar a realização dessas atividades. Quando um ambiente físico responde às necessidades dos usuários tanto em termos funcionais (físico/cognitivos) quanto formais (psicológicos), certamente terá um impacto positivo na realização das atividades.

O transporte tem importante impacto na saúde devido ao seu potencial poluente e, no que tange ao transporte coletivo, também à disseminação de agentes patógenos entre os usuários devido ao confinamento de considerável número de indivíduos simultaneamente e essa influência vem crescendo globalmente diante da necessidade de maior mobilidade urbana (WHO, 2011). Diante desse panorama de necessidade de melhora na mobilidade urbana, a preocupação com o conforto dos usuários nos veículos de transporte urbano, especialmente o conforto térmico, vem adquirindo importância nos últimos anos devido à necessidade de se aumentar a atratividade da utilização do transporte veicular público em relação ao transporte veicular privado individual (RIACHI \& CLODIC, 2014).

O projeto para o conforto térmico é um dos processos mais importantes durante a concepção e produção dos veículos automotores e é baseado no provimento de condições de conforto para os indivíduos através da observância de fatores como temperatura do ar, umidade, fluxo do ar, transferência de calor por radiação e pelas atividades humanas (FANGER, 1972; ASHRAE, 2001; DANCA et al, 2016; NICOL, 1996 apud KÖRBAHTI et al., 2000). Com o suporte de tecnologias de climatização ambiental artificial é possível prover conforto térmico aos usuários do sistema de transporte público, entretanto nota-se que tais tecnologias não são aplicadas de forma sistemática nos ônibus urbanos utilizados no contexto brasileiro, razão pela qual se torna importante verificar a possibilidade de atendimento à parâmetros satisfatórios através da utilização de estratégias passivas para o controle do ganho e da perda térmicos no interior dos veículos.

O ambiente térmico em ônibus de transporte urbano possui peculiaridades em relação ao ambiente térmico em edifícios (DANCA et al, 2016) - nos quais a orientação geográfica é fixa, com taxa de ocupação relativamente baixa e o controle de abertura e fechamento dos vãos de passagem e ventilação é mais eficaz, além de possibilidade de controle do ganho térmico através de dispositivos de proteção como cortinas ou painéis externos - e mesmo em relação a outros veículos automotores como utilitários, carros de passeio, trens e aviões - nos quais os passageiros, geralmente, podem controlar difusores de ar individuais ou até mesmo ajustar a temperatura para um patamar de conforto individual (LIN et al, 2010). Essas peculiaridades estão relacionadas à maior eficiência necessária na troca de ar e no arrefecimento ou aquecimento de acordo com o período do ano e a taxa de ocupação do veículo, que geralmente é elevada. (RIACHI \& CLODIC, 2014).

A avaliação da sensação e do conforto térmico, levando em conta as interações entre o corpo humano e o ambiente, é um tópico importante para assegurar o estado de conforto de passageiros e motorista no interior do veículo. O conforto térmico de humanos é objeto de estudo em diversos trabalhos e uma quantidade considerável de informações foi documentada na literatura e a maioria dos estudos considerou que as condições térmicas são praticamente uniformes e estáveis dentre os ocupantes do veículo (PARSONS, 1993 apud PALA et al, 2014, IVANESCU et al, 2010). Esses estudos foram realizados com diversos enfoques - a abordagem dos mecanismos fisiológicos de controle feita por Gagge et al. (1971), o estudo da avaliação das bases fisiológicas da avaliação do conforto ambiental realizado por Doherty \& Arens (1998), o trabalho de Parsons (1993) apud Pala et al (2014) sobre os Ambientes Térmicos Humanos, que documentou e interpretou 
informações sobre o conforto térmico humano e a publicação Physiology and Human Environment (ASHRAE, 2001) que apresenta todas as equações que regem a relação entre conforto térmico e fisiologia humana - fornecendo dados e informações que possibilitam a compreensão holística dessa relação (DANCA et al, 2016; PALA et al, 2014).

De uma maneira geral, pode-se dizer que o conforto térmico ocorre quando a temperatura do corpo não varia de forma abrupta, a umidade da pele é baixa e o esforço físico para regulação da temperatura corporal é minimizado (MEDEIROS, 2014). Como a noção de conforto térmico varia de acordo com o clima do local a ser analisado e adaptação dos usuários às características bioclimáticas, além de fatores psicológicos e fisiológicos dos mesmos, é possível definir através de um diagrama bioclimático - no qual são observadas relações entre temperatura e umidade relativa do ar obtidas através de uma série climatológica do local - os valores relativos ao conforto higrotérmico durante os meses do ano.

Para que seja possível afirmar que um indivíduo está em situação de conforto térmico, segundo Frota e Schiffer (2005), é necessário que sejam avaliadas as premissas como a neutralidade térmica do indivíduo, que consiste em dissipar para o ambiente todo o calor gerado pelo organismo através de trocas térmicas por radiação, condução e evaporação; a taxa de secreção de suor e a temperatura da pele devem estar dentro de limites aceitáveis em relação às atividades que estejam sendo desenvolvidas, levando-se em conta a energia necessária à realização da atividade e o indivíduo deve estar livre de desconfortos localizados causados pela diferença de temperatura causadas por superfícies com coeficientes de absorção de calor distintos ou corrente de ar. Já Segundo Lamberts (2014), utilizando as informações da ISO 7730 (2005), a condição de zona de conforto para uma pessoa vestida com roupa normal de trabalho (isolamento $=0,6$ clo) está entre $23^{\circ} \mathrm{C} \mathrm{e} 27^{\circ} \mathrm{C}$.

Para Parsons (2000), a avaliação da resposta humana em relação ao ambiente térmico no qual está inserido pode ser realizada de quatro diferentes maneiras, através de a) métodos subjetivos que incluem grupos focais e levam em conta a análise de discurso, b) métodos objetivos nos quais as respostas ao ambiente são medidas diretamente, c) métodos comportamentais no qual se observa o comportamento do indivíduo ou grupo focal em ralação ao ambiente e d) métodos de modelagem nos quais as predições da resposta humana são feitas através de modelos computacionais ou matemáticos.

Para Lin et al (2010), os estudos do ambiente térmico em veículos de transporte urbano de massa podem ser classificados em dois tipos. A primeira abordagem, que consiste em conduzir testes em câmaras com condições controladas em laboratórios, tem a conveniência de possibilitar a condução em larga escala de experimentos em cenários específicos - como, por exemplo, o efeito da aplicação de películas que controlem a entrada de raios infravermelhos nos vidros com diversos fatores de proteção - e muitas das regulações em conforto térmico, como a ISO 14505-2:2006 baseiam-se em resultados obtidos através desta abordagem.

A segunda abordagem, que consiste em conduzir pesquisas de campo sobre o conforto térmico, considera que a influência do comportamento dos usuários não pode ser reproduzida nos experimentos conduzidos em câmaras, resultando em incertezas sobre a aplicação fidedigna em condições reais dos resultados obtidos nestes testes realizados sob condições controladas. Os estudos que se enquadram nesta abordagem são realizados em campo para que seja possível analisar as variantes fisiológicas, psicológicas e comportamentais e, por isso, estão aptas a determinar como determinados grupos focais relacionam-se com o ambiente térmico de maneiras que não podem ser completamente abordadas por modelos matemáticos de equilíbrio fisiológico do calor. Neste âmbito, Lin et al (2010) constataram que as preferências para regulação do conforto térmico entre usuários de linhas de ônibus de longa e curta distância diferem entre si. Passageiros em jornadas curtas (cerca de $30 \mathrm{~min}$ em velocidade média de $40 \mathrm{~km} / \mathrm{h}$ ) preferem ajustar o fluxo de ar, 
enquanto passageiros de jornadas longas (cerca de $60 \mathrm{~min}$ a $100 \mathrm{~km} / \mathrm{h}$ ) preferiram ajustar a incidência solar abrindo ou fechando as cortinas.

No Brasil, as características físicas dos veículos para transporte coletivo urbano de passageiros são definidas pela NBR15570 (ABNT, 2011) que traz as diretrizes metrológicas e ergonômicas a serem atendidas na elaboração do projeto. Devido à grande variação de características climáticas nacionais, que pode ser verificada através da divisão do território brasileiro em oito zonas bioclimáticas com características distintas pela NBR15220-3 (ABNT, 2005) , que influenciam também nas condicionantes da zona de conforto higrotérmico, fazse necessário verificar se o modelo padronizado atende às necessidades dos usuários na cidade de juiz de fora, inserida na zona bioclimática 3 , sem que haja sistema ativo de controle de temperatura e umidade em operação no veículo. No que tange a avaliação do ambiente térmico no interior dos veículos, não dispomos de regulação nacional, entretanto as normas ISO 14505-1:2007, ISO 14505-2:2006 e ISO 14505-3:2006, que tratam da ergonomia do ambiente térmico em veículos, apresentam formas de avaliação que possibilitam o estudo e compreensão do problema.

\section{NORMALIZAÇÃO}

A análise do ambiente térmico no interior da cabine de um veículo correlaciona diversas variáveis e pode ser realizada através de diferentes abordagens. Como resposta a essas diferentes formas de avaliação possíveis, as normas apresentam metodologias e procedimentos a serem utilizados para que se tenha resultados os mais confiáveis possíveis quando da abordagem que leve em conta variáveis ambientais e fisiológicas - que podem ser aplicadas em modelos matemáticos de previsão, gerando resultados objetivos - ou pessoais e psicológicos, que tratam da percepção que o indivíduo tem sobre o ambiente e podem variar individualmente. (ORMUZ \& MUFTIC, 2004)

As normas brasileiras para avaliação do conforto térmico são predominantemente direcionadas à aplicação em edificações - NBR 15220 (ABNT, 2005), NBR 16401 (ABNT, 2008), NBR 15575 (ABNT, 2013) - sendo que a NBR 15570 (ABNT, 2011), que traz as especificações técnicas para fabricação de veículos de características urbanas para transporte coletivo de passageiros, apresenta brevemente requisitos de projeto e avaliação parcial - como no caso do isolamento do motor - que visam à obtenção do conforto térmico, sem que, no entanto apresente uma metodologia de avaliação do ambiente como um todo. No caso de veículos dotados de sistemas de condicionamento de ar, é possível aplicar subsidiariamente a NBR 16401-2 (ABNT, 2008).

Ainda no Brasil, estão em vigor as normas regulamentadoras NR15: Atividades e Operações Insalubres (BRASIL, 1978), que caracteriza e descreve condições ambientais de locais de trabalho que podem trazer riscos para indivíduos expostos a limites máximos ou mínimos em relação a diferentes agentes físicos e químicos atuantes. Esta norma pode ser utilizada como auxílio da obtenção do parâmetro de conforto higrotérmico, conforme estudado por Pereira (2015).

Há significativa gama de normas internacionais que tratam sobre o tema da avaliação do conforto no ambiente térmico interior, sendo as principais a ISO 14505, que trata diretamente sobre o assunto aplicado a veículos e a ASHRAE 55 (ASHRAE, 2013) que, embora não se refira especificamente à avaliação em veículos, define as condições de conforto térmico ambiental para a ocupação humana levando em consideração fatores como a umidade relativa do ar, por exemplo, considerada como fator influente se menor que $30 \%$ ou maior que $70 \%$ (ZHOU, 2013).

De maneira mais abrangente, lida \& Guimarães (2016) discute os mecanismos de termorregulação, os efeitos fisiológicos do calor para atingir o conforto térmico em diferentes situações ambientais. 
Realizando um apanhado das normas ISO EN 7243:1989, ISO EN 7730:2005 e ISO EN 7933:2004 encontramos fatores pessoais tais como vestimentas, atividades desempenhadas e postura influenciam a percepção de calor em diferentes sujeitos.

Medeiros (2014) indicam a ISO 14505:2007 - Ergonomics of the thermal environment -Evaluation of thermal environments in vehicles como a de maior relevância em vigência no contexto da avaliação do ambiente térmico em veículos, uma vez que é a mais utilizada em escala mundial pelas montadoras de veículos no desenvolvimento e avaliação de conformidade de seus produtos, razões pelas quais daremos ênfase em seu estudo. A referida norma ISO é segmentada em três partes, sendo que a primeira traz os princípios e métodos para determinação do stress térmico, a segunda indica como deve ser determinada a temperatura equivalente e a terceira parte define como se deve avaliar o ambiente térmico através da análise da resposta subjetiva dos indivíduos.

Na primeira parte, ISO 14505-1:2007 - Principles and methods for assessment of thermal stress, determina-se que o ambiente térmico no interior dos veículos sofre influências tanto das condições climáticas do meio externo quanto da capacidade do sistema HVAC (Heating Ventilation and Air-Conditioning) em agir no ambiente interno reduzindo os efeitos desfavoráveis da influência do meio externo. A norma direciona a avaliação do ambiente térmico interno de acordo com os efeitos verificados nas condições de stress por calor (heat stress), stress pelo frio (cold stress) ou desconforto térmico (thermal discomfort).

Em situações de stress por calor, nas quais se verifica que a perda de calor pelo organismo para o ambiente em escala inferior à necessária para manutenção do equilíbrio térmico, indica-se a aplicação subsidiária dos métodos estabelecidos pela ISO 7243:1989 - Hot environments -- Estimation of the heat stress on working man, based on the WBGT-index (wet bulb globe temperature), que apresenta um método para a avaliação dos efeitos do calor sobre um indivíduo em período representativo de tempo, e pela ISO 7933:2004 Ergonomics of the thermal environment -- Analytical determination and interpretation of heat stress using calculation of the predicted heat strain, que traz um método de avaliação e interpretação do stress térmico experimentado em ambientes quentes, descrevendo um modelo de previsão da taxa de suor e temperatura interna do corpo em resposta às condições externas.

Em situações de stress pelo frio, nas quais se verifica a perda de calor pelo organismo para o ambiente em escala consideravelmente superior à necessária para manutenção do equilíbrio térmico - sobrecarregando os esforços fisiológicos do corpo para manter o organismo aquecido - recomenda-se a aplicação da norma ISO 11079:2007 - Determination and interpretation of cold stress when using required clothing insulation (IREQ) and local cooling effects, que especifica métodos e estratégias para determinação do stress térmico devido à exposição a ambientes frios, que podem ser aplicados em situações ocasionais, intermitentes ou contínuas, em ambientes internos ou externos.

Em situações de desconforto térmico, considera-se que incômodos localizados ocorram devido à assimetria térmica entre as diversas partes do corpo devido à exposição a diferentes condições climáticas (como, por exemplo, a situação de aquecimento devido ao contato da parte posterior da coxa com o assento ou a ventilação localizada), quando em situações de neutralidade térmica do corpo como um todo em relação ao ambiente. Neste caso é possível a aplicação de dois métodos distintos. O primeiro propicia uma análise generalista em relação ao corpo, sendo representado pela ISO 7730:2005 - Analytical determination and interpretation of thermal comfort using calculation of the PMV and PPD indices and local thermal comfort criteria, que apresenta métodos de predição da sensação térmica geral a grau de desconforto de indivíduos expostos a ambiente térmicos próximos à neutralidade, possibilitando a análise e interpretação do conforto térmico através do cálculo do PMV (Predicted Mean Vote) e do PPD (Predicted Percentage of Dissatisfied) e do conforto térmico localizado em condições ambientais consideradas aceitáveis para 0 conforto térmico geral bem como as que representam o desconforto localizado. O segundo, 
que se trata de uma avaliação mais detalhada, consiste na aplicação da ISO 14505-2:2006 que será apresentada a seguir.

$\mathrm{Na}$ segunda parte, ISO 14505-2:2006 - Determination of equivalent temperature, apresentam-se diretrizes para a avaliação das condições térmicas no interior das cabines dos veículos, podendo também ser aplicada a outros espaços confinados com condições climáticas assimétricas, sendo primariamente concebida para avaliação das condições térmicas em situações em que o desvio em relação à neutralidade térmica é relativamente pequeno. Esta norma baseia-se na determinação da temperatura equivalente para verificação de sua aplicabilidade - uma vez que é possível determinar a relação entre a temperatura medida no local e a ideal, na qual teoricamente haveria neutralidade do corpo em relação ao ambiente pela troca de calor sensível entre eles na mesma proporção, através da determinação da temperatura equivalente, que recebe diferentes abordagens de acordo com o objetivo da avaliação - e na aplicação de sensores térmicos em manequins que simulem indivíduos ou sobre as roupas de indivíduos reais, realizando-se a divisão do corpo em zonas de medição em ambos os casos. A confiabilidade do método poderia ser tratada com cautela quando a evaporação da pele, a transpiração e outros fatores humanos está envolvida.

O uso da termografia infravermelha na previsão do conforto em veículos é uma abordagem que tem sido proposta por alguns autores na medição da variação de temperatura em relação à temperatura da pele humana, como mostrado por Alahmer et al (2011). Usando-se técnicas de infravermelho, com a termografia é possível obter medições em tempo real de superfícies de temperatura dentro da cabine veicular além de roupas e partes do corpo visíveis dos seres humanos. Além disso, a Norma ISO 14505 parece ser mais sensível aos ambientes quentes, enquanto menos sensíveis aos ambientes frios, em comparação com o modelo de conforto térmico proposto pela Universidade da Califórnia - Berkeley (HODDER \& PARSONS, 2008).

$\mathrm{Na}$ terceira parte, ISO 14505-3:2007 - Evaluation of thermal comfort using human subjects, apresenta-se diretrizes e especifica-se um método padrão de testes para a verificação, através da percepção humana, do conforto térmico nos veículos. A avaliação não se restringe a um modal em particular e possibilita a avaliação e verificação através de princípios gerais, que podem ser utilizados para mensurar e determinar o desempenho do ambiente térmico em dada condição de interesse fazendo com que encontre aplicação também no desenvolvimento e avaliação do produto. Para os modais nos quais o usuário encontra-se diretamente exposto ao ambiente externo, sem a existência de cabines, a velocidade de deslocamento $e$ as condições meteorológicas podem interferir excessivamente nas avaliações, entretanto os princípios desta norma continuam aplicáveis. É possível ainda sua aplicação para passageiros e operadores, uma vez que não interfere na operação segura do veículo.

Estes métodos quantificam as respostas individuais através de questionários elaborados com escalas subjetivas, indicadas pela norma, baseadas em fatores psicológicos relevantes ao ambiente térmico no qual os participantes estão inseridos. Após a coleta e organização dos dados, compara-se o obtido com os parâmetros indicados para que seja possível a verificação de atendimento ou não aos requisitos. Apesar de subjetivos, os métodos que utilizam a avaliação de indivíduos em relação à situação do ambiente térmico mostram-se bastante válidos por permitirem uma resposta direta à dada situação. Caso necessário, para que se obtenha uma avaliação mais completa, pode-se ainda complementar a avaliação com dados objetivos fornecidos através da aplicação das metodologias descritas nas outras partes da norma. (MEDEIROS, 2014). 


\section{PROPOSTA METODOLÓGICA SIMPLIFICADA}

Devido à relativa dificuldade de aplicação da norma ISO, visto que o atendimento aos preceitos normalizados em suas três partes depende da aplicação de metodologias trabalhosas, nos casos em que se deseja realizar estudos preliminares para verificação das condições do ambiente térmico, propõe-se, então, uma metodologia simplificada para a avaliação da situação de conforto no interior do veículo, que será descrita a seguir.

Tomando-se por base as normas ISO 14505:2006 e NBR 15570:2011, dentre os índices apresentados, foram definidas como variantes a serem aferidas a temperatura de bulbo seco (uma vez que indica a temperatura do ar, devendo-se estar atento à proximidade de fontes de calor radiante, para que as medidas não sejam influenciadas), temperatura de bulbo úmido (que tem relação com o resfriamento evaporativo, que interfere na sensação de conforto), a umidade relativa do ar (que é a relação entre a pressão do vapor do ar momentânea e a pressão de vapor do ar máxima em situação de saturação), a velocidade e a temperatura do ar em movimento no interior do veículo (que são fatores diretamente ligados à sensação de conforto térmico uma vez que atuam na camada térmica limite de contorno do corpo humano, renovando o ar da envoltória e possibilitando a troca de calor com o ambiente) e a temperatura de superfícies internas (para verificação de possíveis fontes de calor radiante que venham a interferir nas medições).

A partir dos procedimentos de medição preconizados pelas normas decidiu-se, por se tratar o trabalho de uma proposta de metodologia simplificada, realizar as medições no ponto central do veículo, a uma altura de $1,10 \mathrm{~m}$ do piso, que é comum a passageiros sentados ou em pé. A decisão pela unificação dos pontos de medição no ponto central se baseia no fato de que, devido à implantação de portas centrais nos veículos para atendimento a critérios de acessibilidade, os três pontos de medição normalizados passaram a ter características semelhantes. Após a realização das medições, propõe-se a utilização do diagrama de temperaturas efetivas (LEHMANN, 1960 apud IIDA \& GUIMARÃES, 2016) para cruzamento dos dados aferidos e verificação da presença ou não da zona de conforto. Para a proposição da simplificação da metodologia foram deliberadamente desconsideradas a influência da atividade, sendo considerados os usuários em relação de repouso e equilíbrio térmico com o ambiente, e da interferência da indumentária na termorregulação do organismo.

\section{APLICAÇÃO DA METODOLOGIA}

Foram realizadas medições no interior do veículo em situação de veículo completamente ocupado (60 passageiros, dos quais 45 sentados e 15 em pé) e em situação de veículo parcialmente ocupado (30 passageiros sentados) utilizado no transporte de alunos da Universidade Federal de Juiz de Fora entre os diversos prédios do Campus Juiz de Fora desta instituição e que possui trajeto circular com duração de, aproximadamente, 30 minutos, durante o intervalo de uma semana do período letivo em situação de inverno.

As medições de temperatura de bulbo seco e umidade relativa do ar no exterior do veículo foram realizadas por termo higrômetro com função meteorológica da fabricante Instrutemp, modelo ITHW1280 (Figura 3, instrumento 1), após estabilização de 24 horas.

A medição da temperatura de bulbo úmido, da temperatura de bulbo seco e da humidade relativa foi realizada através de termo higrômetro da fabricante Instrutherm, modelo HTR157 (Figura 1, instrumento 2). O aparelho foi mantido ligado durante as 24 horas que antecederam as medições para estabilização da umidade relativa aferida e, durante a medição no interior do veículo foram coletadas medições realizadas a cada 5 minutos, tempo informado como o de resposta rápida pelo fabricante. Os dados aferidos foram coletados por datalogger e organizados em planilhas digitais. 
A velocidade e temperatura do ar no interior do veículo foram aferidas por termo anemômetro digital de fio quente da fabricante Instrutherm, modelo TARF-180 (Figura 1, instrumento 4), e registrada em intervalos de dois segundos entre as medições, sendo registradas a temperatura do ar em graus Celsius e a velocidade do ar em metros por segundo.

A medição da temperatura das superfícies no interior do veículo foi realizada por termômetro infravermelho da fabricante ICEL, modelo TD-990 (Figura 1, instrumento 1), nas áreas de piso, vedação lateral, teto, vidros e proteção do motor.

Figura 1 - Instrumentos utilizados nas medições.
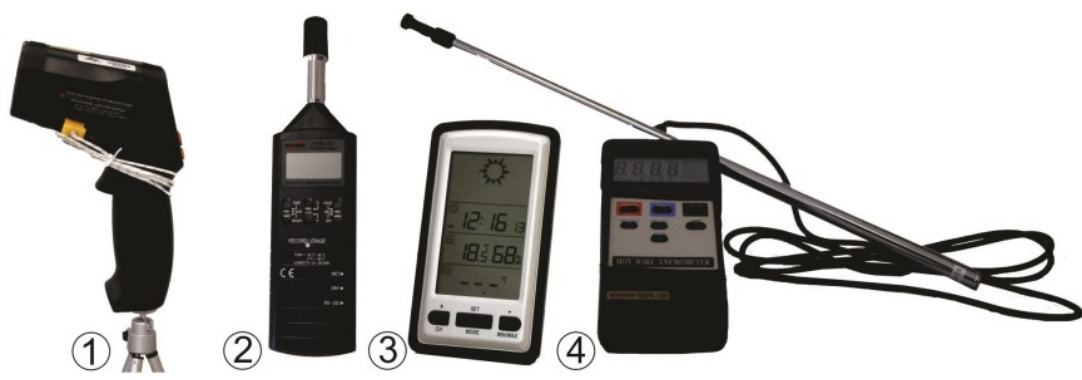

Fonte: elaboração própria.

A partir da temperatura das superfícies apresentada na tabela I verificou-se não haver interferência devido à irradiação de calor, uma vez que as superfícies próximas ao ponto de medição não apresentam variação significativa em relação à temperatura ambiente. Embora a envoltória do motor esteja em temperatura um pouco mais elevada, a distância entre estes permite desconsiderar a influência.

Tabela 1 - Temperatura radiante $\left({ }^{\circ} \mathrm{C}\right)$ das superfícies internas

\begin{tabular}{cccccc}
\hline Piso & Janela & Poltrona & Motor & Parede & Teto \\
\hline 25,7 & 21,8 & 23,6 & 29,4 & 23,2 & 23,6 \\
\hline
\end{tabular}

Fonte: elaboração própria

Após a realização e organização das medições e organização dos dados obtidos, aplicou-se o diagrama de temperaturas efetivas de Lehmann, de forma a verificar a existência ou não de conforto térmico.

Tabela 2 - Média dos parâmetros aferidos

\begin{tabular}{cccccc}
\hline HORA & TBS $\left({ }^{\circ} \mathrm{C}\right)$ & $\mathrm{TBU}\left({ }^{\circ} \mathrm{C}\right)$ & UR $(\%)$ & $\mathrm{V}$ ar $-\mathrm{m} / \mathrm{s}$ & $\mathrm{T}$ ar $\left({ }^{\circ} \mathrm{C}\right)$ \\
\hline $11: 45$ & 18,4 & 15,6 & 78 & 0,1 & 21,1 \\
$11: 50$ & 19,2 & 16 & 75,4 & 0,2 & 20,6 \\
$11: 55$ & 20,2 & 16,3 & 73,4 & 0,2 & 21,7 \\
$12: 00$ & 20,7 & 17 & 71,5 & 0,1 & 22,4 \\
$12: 05$ & 21,3 & 17,1 & 69,3 & 0,3 & 22,8
\end{tabular}




\begin{tabular}{llllll}
$12: 10$ & 21,8 & 17,5 & 67,1 & 0,2 & 22,8 \\
$12: 15$ & 22,3 & 17,7 & 66,3 & 0,5 & 22,5 \\
\hline
\end{tabular}

Fonte: elaboração própria.

Relacionando os dados obtidos pela média semanal das medições no diagrama, podemos afirmar que para o horário de $12 \mathrm{~h} 00 \mathrm{~min}$, por exemplo, em princípio, os usuários não estariam em conforto térmico no interior do ônibus, uma vez que o ponto de intersecção entre as variáveis temperatura de bulbo seco (TBS), temperatura de bulbo úmido (TBU) e umidade relativa (UR) não está contido na zona de conforto indicada pelo diagrama.

Figura 2 - Diagrama de temperaturas efetivas

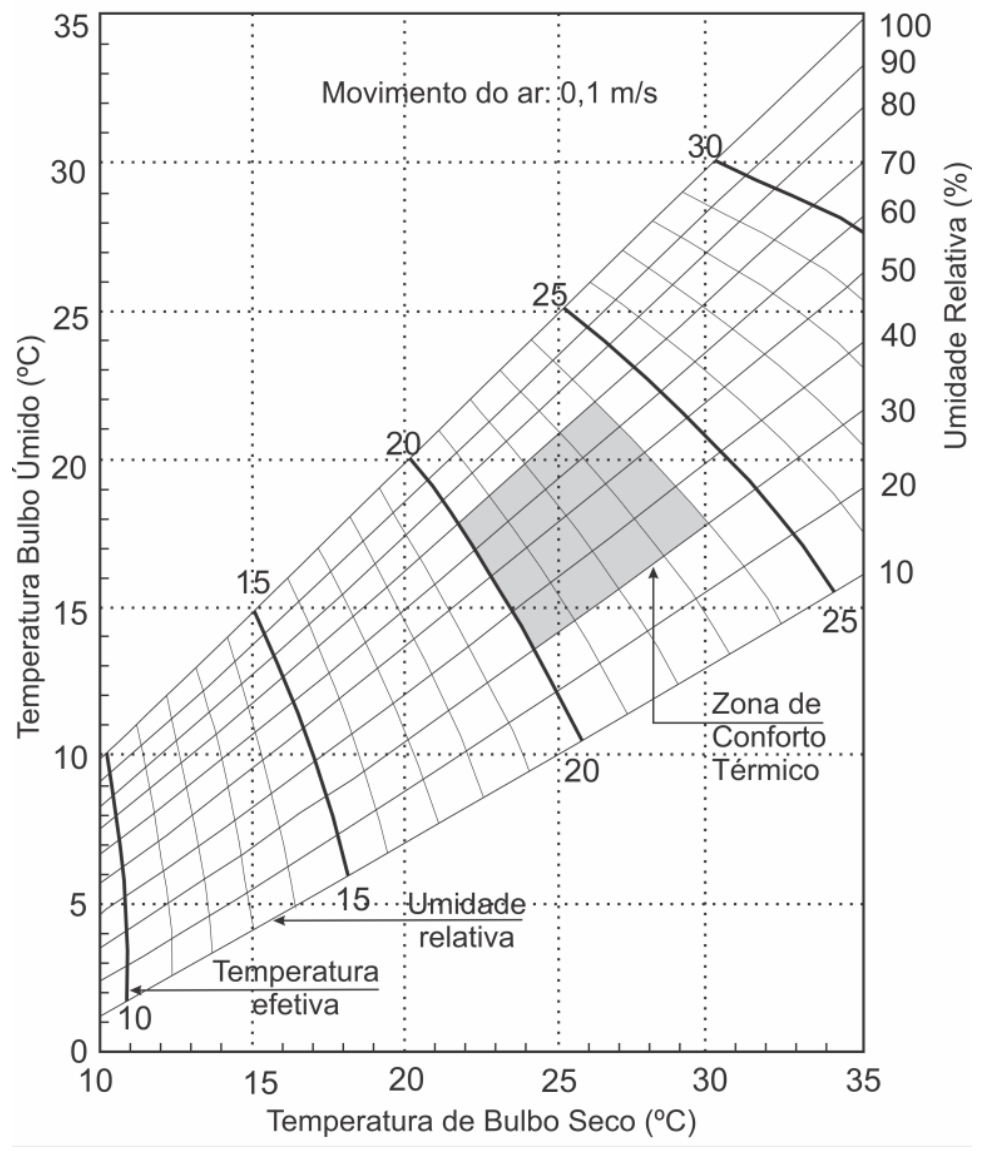

Fonte: Adaptado de Lehmann, 1960 apud lida \& Magalhães, 2016.

Comparando o gráfico e a tabela das medidas externas, é possível perceber que no início das viagens, com o ônibus parado em seu ponto final e com as janelas randomicamente abertas, a umidade relativa do ar encontra-se mais próxima da situação externa. Com o decorrer da viagem, as trocas de ar no interior do veículo reduzem a umidade relativa, enquanto as temperaturas de bulbo seco elevam-se devido à presença humana no recinto $\mathrm{e}$ a temperatura de bulbo úmido segue este padrão devido à redução da umidade relativa do ar, conforme esperado nesta situação segundo a literatura consultada neste artigo. A unidade de velocidade do ar foi transformada de $\mathrm{m} / \mathrm{s}$ para $\mathrm{cm} / \mathrm{s}$ para permitir melhor visualização. 
Tabela 3 - Média das variáveis externas semanais

\begin{tabular}{cccccc}
\hline \# (HORA) & $\mathrm{TBS}\left({ }^{\circ} \mathrm{C}\right)$ & $\mathrm{TBU}\left({ }^{\circ} \mathrm{C}\right)$ & $\mathrm{UR}(\%)$ & $\mathrm{V}$ ar $-\mathrm{m} / \mathrm{s}$ & $\mathrm{T} \operatorname{ar}\left({ }^{\circ} \mathrm{C}\right)$ \\
\hline $11: 45$ & 19,7 & 17,5 & 80 & 6,1 & 21,3 \\
\hline
\end{tabular}

Fonte: elaboração dos autores

Figura 3 - Evolução dos parâmetros.

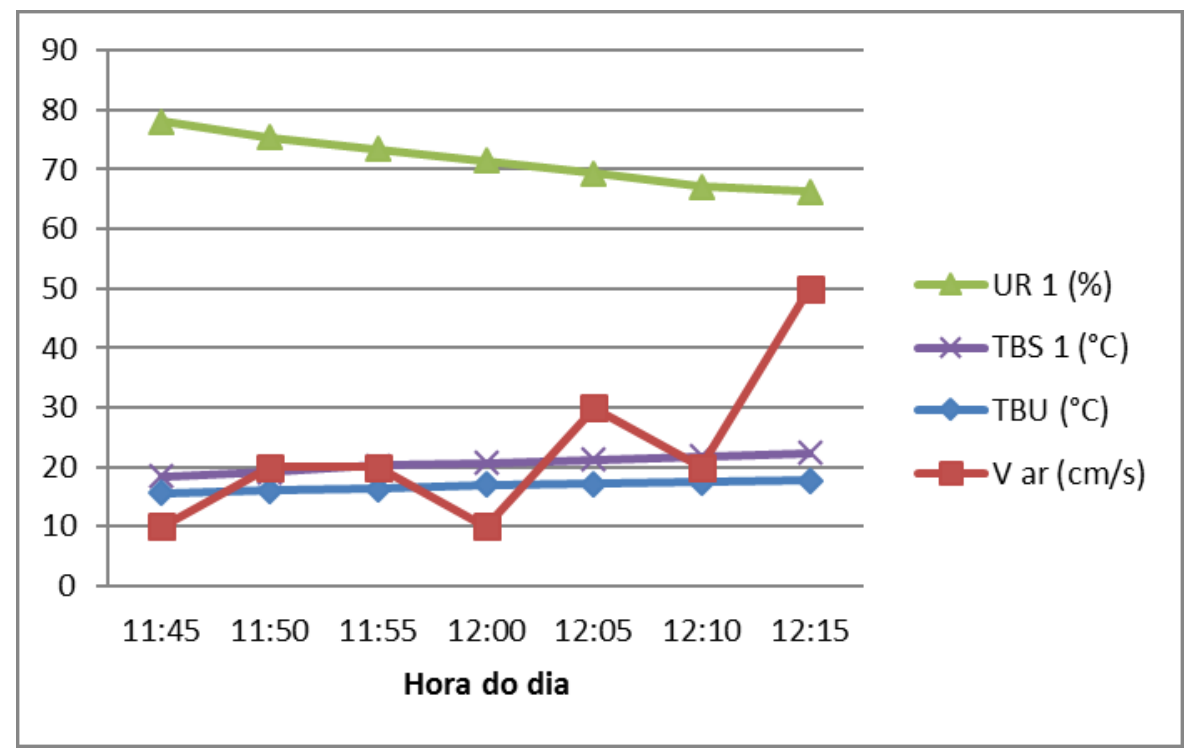

Fonte: Elaboração própria.

\section{CONSIDERAÇÕES FINAIS}

Percebeu-se que os parâmetros selecionados para aplicação nesta proposta metodológica simplificada são representativos das normas vigentes, resguardadas as devidas abrangências e aprofundamentos de estudo. Devido à coleta de dados em situação de inverno, novos estudos podem ser realizados em situação de verão para a verificação da pertinência dos resultados fornecidos pelo método proposto e possível aplicação em todos os períodos sazonais sem, no entanto, prejudicar a pertinência de aplicação desta metodologia.

Projetando um possível comportamento das normais climatológicas em períodos mais quentes do ano, utilizaram-se dados da série histórica da estação meteorológica automática A518 do Instituto Nacional de Meteorologia, localizada no Campus Sede da Universidade Federal de Juiz de Fora. Embora os dados sejam relativos à medida do ambiente externo, possibilitam inferir de forma confiável o estado de conforto em tal situação.

Por fim, vale ressaltar que a simplificação proposta reorganiza métodos e procedimentos já existentes e amplamente estudados e difundidos, facilitando uma análise preliminar para verificação de conforto no ambiente térmico do interior dos veículos e, assim, subsidia estudos mais aprofundados nas situações de possível stress térmico por calor ou frio verificadas, aplicando-se então os requisitos exigidos pelas normas vigentes. 


\section{REFERÊNCIAS BIBLIOGRÁFICAS}

ALAHMER, A.; MAYYAS, A.; MAYYAS, A. A.; OMAR, M. A.; SHAN, D. Vehicular thermal comfort models; a comprehensive review. Applied Thermal Engineering, v. 31, n. 6-7, p. 995-1002, 2011.

ANSI/ASHRAE. Standard 55: Thermal Environment Conditions for Human Occupancy; 2013.

ASHRAE. Fundamentals Handbook. American Society of Heating, Ventilating and Air-Conditioning Engineers. Atlanta. USA, 2001.

ASSOCIAÇÃO BRASILEIRA DE NORMAS TÉCNICAS. NBR 15570: Transporte - Especificações técnicas para fabricação de veículos de características urbanas para transporte coletivo de passageiros. Rio de Janeiro: ABNT, 2011.

NBR 15220-3: Zoneamento Bioclimático Brasileiro e diretrizes construtivas para habitações unifamiliares de interesse social. Rio de Janeiro: ABNT, 2005.

. NBR 15575: Edificações Habitacionais - Desempenho. Rio de Janeiro: ABNT, 2013.

ABNT, 2008.

NBR 16401: Instalações de ar-condicionado - sistemas centrais e unitários. Rio de Janeiro:

KÖRBAHTI, B.; KUCUR, M.; KAYKAYOGLU, C. R. An Innovative Computational Model of the Thermal Comfort Conditions in City / Inter-City Buses. In: ECCOMAS 2000 - European Congress on Computational Methods in Applied Sciences and Engineering. Barcelona, 11-14 Set. 2000.

DOHERTY, T.J.; ARENS, E. Evaluation of the physiological bases of thermal comfort models. ASHRAE Trans. 94 (Part 1), p. 1371-1385, 1998.

FANGER, P. O. Thermal Comfort: Analysis and Applications in Environmental Engineering. McGrawHill Book Company: New York, 1972.

FROTA, A. B.; SCHIFFER, S. R. Manual de Conforto Térmico: Arquitetura, Urbanismo. São Paulo: Studio Nobel, 2001.

GAGGE, A. P.; STOLWIJK, J. A. J.; NISHI, Y. An Effective Temperature Scale Based on a Single Model of Human Physiological Temperature Response. ASHRAE Transactions, Vol. 77, p. 247-262, 1971.

HODDER S. G.; PARSON K. The effects of solar radiation and black body re-radiation on thermal comfort. Applied Ergonomics, v.51, p. 476-490, 2008.

IIDA, I.; GUIMARÃES, L.B. de M. Ergonomia: Projeto e Produção. São Paulo: Blucher, 2016.

INTERNATIONAL STANDARD ORGANIZATION. ISO 14505-1: Ergonomics of the thermal environment - Evaluation of thermal environments in vehicles. Part 1: Principles and methods for assessment of thermal stress. Genebra, ISO, 2007.

ISO 11079: Ergonomics of the thermal environment -- Determination and interpretation of cold stress when using required clothing insulation (IREQ) and local cooling effects. Genebra, ISO: 2007.

ISO 14505-2: Ergonomics of the thermal environment - Evaluation of thermal environments in vehicles. Part 2: Determination of equivalent temperature. Genebra, ISO, 2006.

ISO 14505-3: Ergonomics of the thermal environment - Evaluation of thermal environments in vehicles. Part 3: Evaluation of thermal comfort using human subjects. Genebra, ISO:2007. 
ISO 7243: Hot environments: estimation of the heat stress on working man, based on the WBGT-index (wet bulb globe temperature). Genebra: ISO, 1989.

. ISO 7730: Moderate thermal environments - Determination of the PMV and PPD indices and specification of the conditions for thermal comfort. Genebra, ISO:2005.

ISO 7933: Hot environments: analytical determination and interpretation of thermal stress using calculation of required sweat rate. Genebra: ISO, 1989.

ORMUŽ, K.; MUFTIĆ, O. Main Ambient Factors Influencing Passenger Vehicle Comfort. In: Proceedings of 2nd International Ergonomics Conference, Zagreb, Out. 21-22, 2004.

LAMBERTS, R. Conforto e Stress Térmico. Apostila. Centro Tecnológico - Departamento de Engenharia Civil. Universidade Federal de Santa Catarina - SC. 2014.

IVANESCU, M.; NEACSU, C. A.; TABACU, I. Studies of the Thermal Comfort Inside of the Passenger Compartment Using the Numerical Simulation. In: International Congress Motor Vehicles \& Motors 2010, Kragujevac, Out. 7-9. 2010.

MEDEIROS, E. G. S. de. Estudo Termoambiental em Viaturas Utilizadas nos Serviços de Radiopatrulhamento no Estado da Paraíba. (Dissertação de Mestrado). Universidade Federal da Paraíba, 2014.

BRASIL. Ministério do Trabalho e Emprego. NR 15: Atividades e operações insalubres. Aprovada pela Portaria $n^{\circ} 3214$ do Ministério do Trabalho e alterada pela Portaria $n^{\circ} 203$, de 28 de janeiro de 2011.

Parsons, K. C. Human Thermal Environments. Bristol: Taylor \& Francis Inc., 1993.

Parsons, K. C. Environmental ergonomics: a review of principles, methods and models. Applied Ergonomics, v. 31, p. 581-594, 2000.

DANCA, P.; VARTIRESA, A.; DOGEANUA, A. An Overview of Current Methods for Thermal Comfort Assessment in Vehicle Cabin. Energy Procedia, v. 85, p. 162-169, 2016.

PEREIRA, R. N. Estudo do Conforto Ambiental nos Veículos de Transporte Urbano Coletivo da UESB e de Itapetinga- Bahia. (Dissertação de Mestrado). Universidade Estadual do Sudoeste da Bahia, 2015.

RIACHI, Y. CLODIC, D. A numerical Model for Simulating Thermal Comfort Prediction in Public Transportation Buses. International Journal of Environmental Protection and Policy, v. 2, n. 1, p. 1-8, 2014.

LIN, T.; HWANG, R.; HUANG, K.; SUN, C.; HUANG, Y. Passenger Thermal Perceptions, Thermal Comfort Requirements, and Adaptations in Short and Long-Haul Vehicles. International Journal of Biometeorology, v. 54, p. 221-230, 2010.

PALA, U.; OZ, H. R. An Investigation of Thermal Comfort Inside a Bus During Heating Period Within a Climatic Chamber. Applied Ergonomics, v. 48, p. 164-176, 2015.

VILLAROUCO, V.; ANDRETO, L. F. M. Avaliando Desempenho de Espaços de Trabalho Sob o Enfoque da Ergonomia do Ambiente Construído. Produção, v. 18, n. 3, p. 523-539, 2008.

WHO - World Health Organization. Urban Transport and Health. In: Sustainable Transport: A Sourcebook for Policy-makers in Developing Cities. Bonn, 2011.

ZHOU, Q. Thermal Comfort in Vehicles. Faculty Of Engineering And Sustainable Development, 2013 